\title{
An On-Situ Study of Stability Analysis on Slopes Using Undrained Shear Strength Parameters
}

\author{
Kayal R \\ Department of Civil Engineering, TRP Engineering College,India
}

\begin{abstract}
The slope stability problems in residual soil are receiving increasing attention in recent years. The stability of slope is one of the important criteria where consider worldwide for a wide range of engineering projects. The rainfall seems to be the most common cause for landslide in residual soil slope. After a period of continuous rainfall, soil becomes saturated and a wetting front is developed because of infiltration of rainwater into the ground and into the slope surface respectively. The objective of the paper is to find threshold slope based on undrained shear strength parameters.
\end{abstract}

Keywords: Landslide, Rainfall, Slope stability, Threshold slope, Undrained shear strength parameters.

\section{INTRODUCTION}

A soil mass, which is bound by sloping surface, is subjected to shearing stresses on all its internal surfaces due to its self-weight, which tries to pull the soil mass downward and outward towards a more nearly horizontal surface. The stability of slope should be thoroughly analyzed since their failure may lead to loss of human life as well as economic loss. Slope stability problems directly or indirectly causes the economy problem to any nation. The type of soil the hilly regains are residual nature and the thickness of the residual soil at a particular location deposes of the rate of rock weathering and availability of erosive forces. Rainfall is seems to be the most common cause of slope failure in residual soil slopes in many counties. After a period of continuous rainfall the soil becomes saturated because of infiltration of the rainwater into the ground. The initial high negative pore water pressure in the soil is eliminated or greatly reduced, causing a large reduction of the effective stress and of the shear strength. As a result the slope become unstable and fails. Numbers of slope failure have been reported during every rainy season in Nilgiri, a hilly region in Tamil Nadu a state of India. This paper summarises the preliminary study carried out to find the stable slope for different height of the hill and threshold slope based on undrained shear strength parameters. The slope analyses were carried out assuming the slopes are both infinite and finite. Finite slope stability analysis was carried out using SVSlope software version 2.3.17.

\section{Literature Review}

Fredlund et .al discussed about the development in slope stability analysis by consider the effect of suction in the unsaturated zone. The shear strength equation for unsaturated soils had gained wide acceptance, and testing procedures had been proposed for measuring the shear strength parameters for unsaturated soil. [1]

Lim et al., (1996) studied the stability of shallow slip surface considering the negative pore-water pressure or matric suction. [2]

Fredlund and Scoular (1999) reviewed several slope stability methods, which have been adopted in the finite element analysis to find the minimum factor of safety. Both the general limit equilibrium and the finite element method of slope stability produced nearly equal factor of safety values. But the critical slip surfaces were different for the factor of safety. [3]

Gasmo et al (2000) studied the infiltration effects on stability of a residual soil slope. The numerical study and the case study were used successfully to study infiltration and its effect on slope stability. The results of the numerical study showed that most infiltration occurs at the crest of the slope. [4]

Manazari and Nour (2000) examined the influence of soil dilatancy on the stability of slope through finite element method and conducted that dilatancy of soil has significant effect on the stability of slope. Higher the dilatancy angle to increase the stability of slope. [5]

Rezaur et al., (2003) reported hydrologic behaviour of residual soil slope in Singapore. Based on monitor the hydrologic slope is critical. A high correlation between the increase in pore-water pressure and the daily rainfall may provide a convenient estimate of the increase in pore-water pressure due to the daily rainfall. [6]

Jaehong et al (2004) studied Shallow failures of slopes in weathered soil were caused by infiltration due to prolonged rainfall. an increase in factor of safety due to the wetting front suction was small, it make either stability or failure for slopes with factors of safety only slightly greater than unity at any field condition.[7] 
Stark et al (2005) this paper discussed the recommendation for selecting the type and magnitude of drained shear strength parameters for analysis of landslides. For slope stability analysis, it has been recommended that the shear strength can be modelled using a stress dependent failure envelope or a friction angle that corresponds to the average effective normal stress acting on the slip surface passing through that particular material instead of using a combination of cohesion and friction angle to represent soil shear strength. Other recommendation for stability analysis includes using effective stress cohesion of zero for residual and fully softened strength situations. [8]

Hsin-Fu et al., (2006) focused for calculating the safety factor for an unsaturated slope distress from rainfall infiltration. The relationship between effective degree of saturation and safety factor indicated linear decrease, and therefore the shear strength gets reduced caused due to water content increase. [9]

\section{Problem Definition}

Based on the literature studies, it was observed that landslide is one of the major problems that cause huge impact on social as well as on economy. Here, work was carried out to find the threshold slope of Kateri road of Nilgiri based on undrained shear strength parameters. This results leads to minimize the landslide on the slope areas during rainfall and it will be horizontally deployed to other slope areas.

\section{Slope Stability Analysis}

There are many different approaches to the analysis of slope stability. The most common methods are based on "limiting Equilibrium". In which it is assumed that the soil is at the verge of failure. The limit equilibrium methods have been used extensively for many years for the analysis of natural and manmade slopes. The basic assumption of the limit equilibrium approach is that coulomb's failure criterion is satisfied along the assumed failure surface, which may be a straight line, circular arc, logarithmic spiral or other irregular surface.

\section{Infinite Slope Analysis}

The shear and normal stresses can be calculated directly from the equations of static equilibrium and then used conversional method for finding the factor of safety. Fig.1 illustrates Kateri Road Slide for which factor of safety is considered as one.

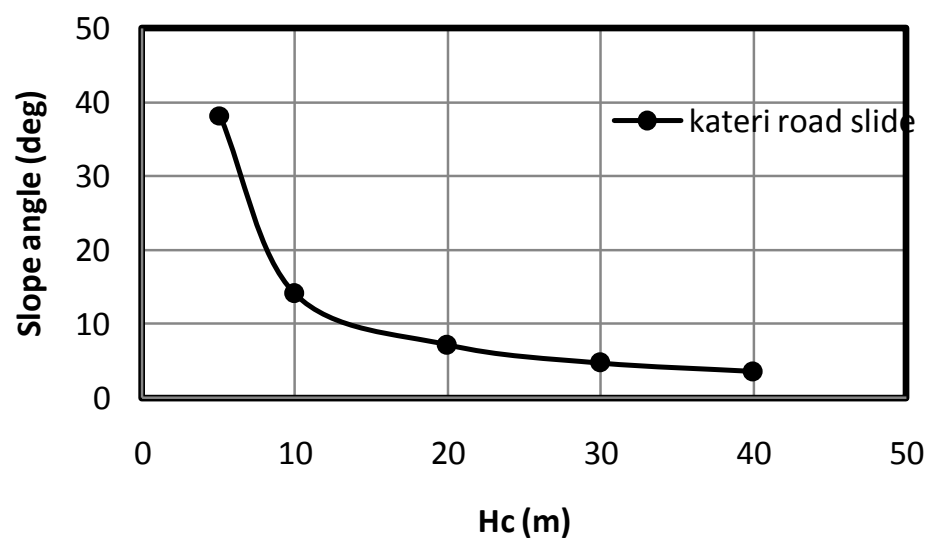

Fig. 1 Threshold slope for kateri road slide

\section{Finite Slope Analysis}

The stability of existing slope is examined using the minimum undrained shear strength parameters, for both the locations are used as same as infinite analysis. Critical height for different slope angle is determined with Ordinary method, Bishop's method, Janbu's method, M-P method and Spencer method by assuming the factor of safety value as 1 for kateri location. The results are plotted as a graph between critical height and slope angle and are shown in Fig. 2. 


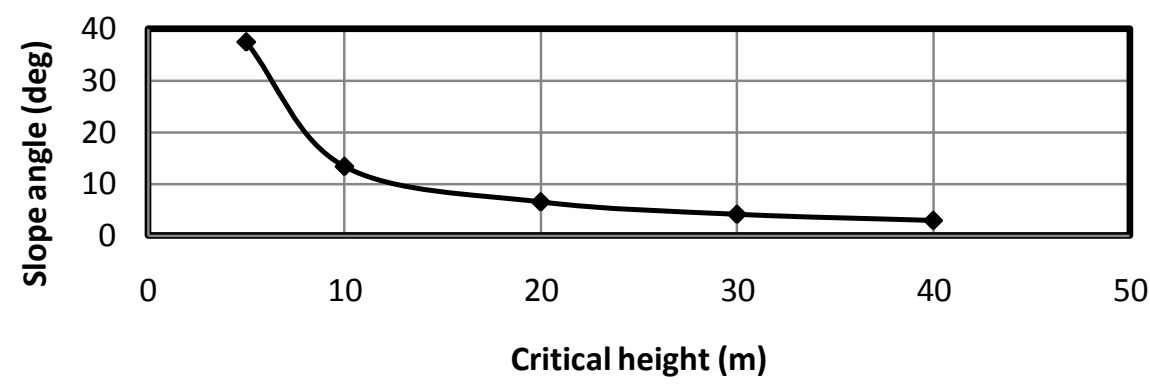

Fig. 2 Threshold slope for Kateri Road Slide

\section{Results And Discussion}

The existing slope and height of slope of Kateri road slide are $38.16^{\circ}$ and $30 \mathrm{~m}$ respectively. Based on the undrained shear strength of the above location, the stable slopes are determined by considering the slope as infinite and finite. They are listed in Table 1.

Table. 1 Stable slope for existing slope of selected location

\begin{tabular}{|c|c|c|}
\hline \multirow{2}{*}{ Location } & \multicolumn{2}{|c|}{ Stable slope for existing height based on undrained shear strength (deg) } \\
\cline { 2 - 3 } & Infinite slope analysis & Finite slope analysis \\
\hline Kateri Road slide & 4.75 & 4.1 \\
\hline
\end{tabular}

Threshold slope for Kateri road slide area is $4^{\circ}$ to $5^{\circ}$. The difference the stable slope based on finite and infinite slope analysis very less. For the above location the threshold slope for different height of slope are also calculated considering the slope as infinite and finite. They are summarised below Table 2 .

Table. 2. Stable slope for a different height of selected location

\begin{tabular}{|c|c|c|}
\hline \multirow{2}{*}{ Height of slope $(\mathrm{m})$} & Stable slope angle as infinite slope (deg) & Stable slope angle as finite slope (deg) \\
\cline { 2 - 3 } & Kateri Location & Kateri Location \\
\hline 40 & 3.55 & 2.9 \\
\hline 30 & 4.75 & 4.10 \\
\hline 20 & 7.15 & 6.50 \\
\hline 10 & 14.08 & 13.38 \\
\hline 5 & 38.16 & 37.51 \\
\hline
\end{tabular}

The difference in the above slope angles are also relatively less. Since the existing slope are stable at present, the probable shear strength parameters for the existing height and slope are also back calculated using finite slope analysis.

\section{Conclusion}

The primary purpose of slope stability analysis is to be contributed towards the safe and economic design of engineering project. Here, the critical height for different slope angle was determined for both the locations by assuming the factor of safety value as one. The scope of study will be extended for above slopes by considering suction values.

\section{References}

[1] Fredlund D.G, "Slope Stability Analysis Incorporating the Effect of Soil Suction", University of Saskatchewan, Canada S7N 0WO,1987, 113-143.

[2] Lim .T. T., Rahardjo .H. Chang M .F and Fredlund D .G. , "Effect of Rainfall on matric suctions in a residual soil slope", Canadian Geotech Journal, vol-33,1996, 618-628.

[3] Fredlund D.G and Scoular R.E.G., "Using Limit Equilibrium Concepts in Finite Element Slope Stability Analysis", International Symposium on Slope Stability Engineering, 1999.

[4] Gasmon J.M., Rahardjo H, and Leong E.C (2000), "Infiltration Effects On Stability Of A Residual Soil Slope", Computers And Geotechnics, Vol 26, 2000, 145-165.

[5] Manzari M.T and Nour M.A , "Significance Dilatancy In Slope Stability Analysis", Journal of Geotechnical and Geoenvironmental Engineering ASCE, 2000, 75-80.

[6] Rezaur .R .B. Rahardjo .H ., Leong .E .C., and Lee .T .T., "Hydrologic behavior of residual soil slopes in Singapore" Journal of Hydrologic Engineering (ASCE), 2003 , 133-144

[7] Jachong Kim, Sangseom Jeong, Seongwan Park and Jitendra Sharina , "Influence of rainfall-induced wetting on the stability of slope in weathered soil", Engineering Geology, 75(3-4), 2004, 251-262.

[8] Stark T.D, Choi H and McCone S , "Drained Shear Strength Parameters For Analysis Of Landslides", Journal of Geothchnical and Geoenvironmental Emgineering ASCE, 2005, 575-588.

[9] Hsin-Fu Yeh, Po-Hsun Chang, Jin-Fa Chan, ands Cheng-Haw Lee (2006), "Instability of unsaturated soil slopes due to infiltration" International symposium on Geohazards,Taiwan. 